\title{
Critical Success Factors of Open Markets on the Internet in Terms of Buyers
}

\author{
Sung Ho Ha and Luo Tao Liu \\ School of Business Administration, Kyungpook National University, \\ Sangyeok-dong, Buk-gu, 702-701 Daegu, Korea \\ hsh@mail.knu.ac.kr
}

\begin{abstract}
Online shopping in open markets becomes increasingly popular with the development of the Internet. The purpose of this study is to formulate and evaluate critical success factors in the open market from the perspective of buyers. Based on an extended technology acceptance model, this study assumes that the success of open markets are influenced by several factors, including perceived website quality, perceived usefulness, third party recognition, satisfaction, and trust. An empirical survey is conducted and questionnaires are collected from the respondents who had experience in using the open markets. The hypotheses are verified by using the structural equation modeling. Testing results are summarized and managerial implications are discussed.
\end{abstract}

Keywords: Open market, e-commerce, extended technology acceptance model, purchase intention.

\section{Introduction}

Open markets provides consumer-to-consumer (C2C) electronic commerce on the Internet. They use online auctions, web forums, chat rooms, and third party listing. They are one of the applications that come close to emulating the success of the other two main e-commerce models, business-to-business (B2B) and business-to-consumer (B2C) [1]. Although there have been many researchers discussing the issues of transaction intention in $\mathrm{B} 2 \mathrm{C}$ e-commerce, a few studies have attempted to explain the factors influencing the adoption of $\mathrm{C} 2 \mathrm{C}$ e-commerce [2], and there has been a few research on the critical factors influencing $\mathrm{C} 2 \mathrm{C}$ purchase intention in the open market. Therefore, it is necessary to conduct an analysis of which factors influence people's intention to take part in online transactions and a study on how to encourage consumers to accept $\mathrm{C} 2 \mathrm{C}$ shopping in the open market.

The transactions in $\mathrm{C} 2 \mathrm{C}$ e-commerce are conducted between two consumers, so it is difficult to build trust between them. A third party then plays an important role in $\mathrm{C} 2 \mathrm{C}$ e-commerce. Under the third party's control, more users are willing to trust open markets. However, there are still many barriers, which deter users from participating in $\mathrm{C} 2 \mathrm{C}$ e-commerce. Security of payment, trust, and privacy policies are the reasons that users are reluctant to shop online. Previous research has found differences between $\mathrm{C} 2 \mathrm{C}$ and $\mathrm{B} 2 \mathrm{C}$ e-commerce, pinpointing that $\mathrm{B} 2 \mathrm{C}$ e-commerce methods have 
limitation to be utilized in $\mathrm{C} 2 \mathrm{C}$ e-commerce [3]. Consumers' purchase intention in the open market has thus proven to be a distinct area of research, and its operation requires the use of new models.

Based on Davis' technology acceptance model (TAM) [4], this study investigates which factors may influence consumers' purchase intention in the open market. Previous studies have suggested that website quality that meets consumer needs could affect consumers' purchase behavior [5]. Therefore, this study modifies TAM and proposes that perceived website quality has an effect on consumer behavior. This study also focuses on the concept of trust. Both perceived website quality and third party recognition affect consumer's trust toward the vendor. Based on these hypotheses, this study investigates the acceptance of $\mathrm{C} 2 \mathrm{C}$ e-commerce in the open market. The remainder of the paper is organized as follows: Section 2 addresses previous relevant research and formulates research hypotheses. Section 3 describes an analysis methodology and presents empirical results. Section 4 concludes this study.

\section{Research Hypothesis and Related Literature}

The model proposed in the paper presents purchase intention as being influenced by direct and indirect relationships with perceived website quality, perceived usefulness, third party recognition, satisfaction, and trust.

\subsection{Perceived Web Site Quality (PWSQ) and Perceived Usefulness (PU)}

As Szymanski and Hise observed [6], a few studies have examined the factors that affect whether online consumers are satisfied with their online experiences. Jeong and Lambert proposed that website quality consisted of six potential dimensions: information accuracy, completeness, relevancy, clarity, ease of use, and navigation quality [7]. According to these studies, website quality can be analyzed by using two major constructs, such as functionality and usability. Functionality relates to content of a website, while usability relates to issues of design. Functionality relates to the information richness of a website, whereas usability refers to the degree of ease with which users can use a website.

Researchers have indicated that the greatest threat to e-commerce is consumer awareness. An individual's perception of the environment would affect his risk and safety assessment [8]. Even if consumers have a positive buying experience, the early concern about the atmosphere could prevent further transactions. In addition, the quality of websites related to perceived usefulness and had an effect on the user's online purchase intention [9]. The website quality was an important driver of consumer perception about the future online activity [10]. Bai et al. [11] have confirmed the relationship between website quality and satisfaction in an e-commerce environment. In addition, Everard and Galletta showed that website quality affected consumer trust in an online store [12]. Jones and Leonard's study confirmed that website quality had an impact on trust in the $\mathrm{C} 2 \mathrm{C}$ e-commerce [3].

In an open market, a website is a medium connecting vendors and buyers. This study thus assumes that perceived website quality (PWSQ) is associated with 
perceived usefulness (PU), satisfaction (SAT), and trust (TRU). The first three hypotheses are listed as follows:

H1: PWSQ of an open market positively influences PU.

H2: PWSQ of an open market positively influences SAT.

H3: PWSQ of an open market positively influences TRU.

TAM has been based on the theory of reasoned action, proposed by Fishbein and Ajzen [13]. TAM predicts information technology acceptance and usage in the workplace and makes IT adoption research more efficient [4]. Its effectiveness has been revealed by numerous empirical studies. Information system usage is regarded as an important success indicator of information systems in the TAM. User satisfaction has been widely used by researchers as an alternative success indicator of information systems and as an indicator of technology acceptance. TAM suggests that perceived usefulness has a direct and significant impact on users' attitudes. Previous research has shown that perceived usefulness has a significant effect on user satisfaction in technology adoption [14] and in electronic markets [15]. Therefore, this study hypothesizes that:

H4: PU positively influences SAT.

\subsection{Third Party Recognition (TPR), Satisfaction (SAT) and Trust (TRU)}

Lee and Turban presented the important relationships between consumer trust in ecommerce and three groups of antecedents: trustworthiness of the Internet merchant, trustworthiness of the Internet shopping medium, and infra-structural factors (effectiveness of third party functions, certification, and effectiveness of security) [16]. Sultan et al. demonstrated that website characteristics (navigation, brand, advice, no errors, presentation, order fulfillment, and community) and consumer characteristics (previous experiences with the Internet and with a particular website) significantly affect trust in a website [17]. Gefen et al. showed how trust and TAM were related to the purchase intention of low-risk goods from vendors [18].

In an e-commerce environment, consumers find it difficult to get comprehensive information. Especially in open markets, vendors deal with buyers as individuals, and most of the goods being traded is not expensive. Because the third party connects vendors and buyers, its recognition (reputation) is found to be a significant factor in an open market. A third party institution has been shown to reduce uncertainty the buyer feels and to increase his trust when making online transactions. McKnight et al. referred it as institution-based trust [19], which is considered as a fundamental requirement in open markets. Third party recognition affected trust in an online shopping environment [20]. In addition, third party recognition was found to be positively related to confidence of buyers and to be negatively related to purchase risk perception. Based on Jones and Leonard's study [3], perception of website quality and third party recognition influenced $\mathrm{C} 2 \mathrm{C}$ e-commerce trust. Therefore, this study hypothesizes that: 


\section{H5: TPR positively influences TRU.}

From Ajzen and Fishbein's research [21], behavior intention was found to be determined by the individual's attitude toward the behavior, and a person's attitude is affected by his beliefs. An empirical study has indicated that trust is strongly related to attitude [22]. In a buyer-seller relationship, buyer's evaluation of trust before a specific exchange is found to have a direct influence on their post-purchase satisfaction [23]. In an e-commerce situation, trust has been empirically found to be a strong predictor of satisfaction [24]. If buyers feel that vendors are trustworthy, they are more satisfied with the open market. Therefore, the following hypothesis is proposed:

H6: TRU positively influences SAT.

\subsection{Purchase Intention (PI)}

It is important to understand purchase intention of buyers, because their behavior can usually be predicted by their intention. Zeithaml and Parasuraman asserted that the purchase intention could be seen as a dimension of behavioural intention [25]. Purchase intention is correlated to actual behavior [21] and this relationship has been empirically tested in hospitality and tourism businesses [26]. In addition, customer satisfaction turns out to be an important factor of behavioural intention in an online business [7].

Satisfaction is a quasi-attitudinal construct and often considered as an attitude [27]. Davis suggested that users' attitudes could affect users' behavioral intention directly [4]. As a result, satisfaction has been investigated as an antecedent to the continuous intention of e-commerce services in technology acceptance [28]. Several researchers in marketing have empirically shown that satisfaction has a significant and positive effect on consumer purchase intention [29]. Information system researchers also have confirmed the relationship between satisfaction and continuous intention of e-commerce services [15]. Thus, this study advances:

\section{H7: SAT positively influences PI.}

TAM stated that perceived usefulness had a direct effect on the user's behavioral intention, because users are more willing to use technology if it can afford benefits. Perceived usefulness mediates the effect of perceived ease of use on behavioral intention. Most empirical studies have provided strong evidence that perceived usefulness directly influences users' intention of adopting new technology [30]. Several empirical studies have supported this 'perceived usefulness-user intention' connection in the open market, including $\mathrm{He}$ et al. [1], for example. The following hypothesis is thus proposed:

\section{H8: PU positively influences PI.}

Many researchers have indicated that trusting trading partners can sometimes increase efficiencies. The action of sharing confidential information creates a situation that may be convenient to one or both partners [31]. This suggests a need for trust. Trust plays a vital role in online business, and it is a critical antecedent of building a 
relationship between buyers and sellers [32]. McKnight et al. suggested that a willingness of purchase was determined by trust [19]. Gefen and Heart suggested that trust significantly influences consumers' purchase intention in an e-commerce [33]. Therefore, this study presents the last hypothesis as follows:

H9: TRU positively influences PI.

\section{Analysis and Results}

\subsection{Characteristics of the Sample}

Scales for perceived usefulness were adopted from studies of He et al. [1]. Measures for perceived website quality, satisfaction, and purchase intention were adopted from Bai et al. [11]. Measures for third party recognition and trust were adopted from Jones and Leonard [3]. All items were measured by 5-point Likert scale with anchors ranging from 'strongly disagree' (1) to 'strongly agree' (5).

The survey was conducted in Korea. Most online shopping users were between 20 and 40 years of age and more than half of them were buying on open markets $(\mathrm{C} 2 \mathrm{C}$ websites). 177 samples were collected (81\% return rate). 19 of these had no C2C experiences in the open markets, and 11 contained incomplete answers or obvious self-contradictions. As a result, 147 responses were used in continued analysis. The characteristics of the sample were as follows: Male and female responders showed even distribution. The respondents were relatively young, so that $87.1 \%$ were between 21 and 30 years old. Most of the samples (80.3\%) were high school graduates, $10.2 \%$ were university graduates, and $9.5 \%$ had a higher education. $9.5 \%$ were employees. Most of the respondents $(78.9 \%)$ bought goods in open markets once or twice a month and often bought goods from Gmarket.com (60.6\%) and Auction.co.kr (38.8\%).

\subsection{Validation of Reliability and Validity}

Structural Equation Modeling (SEM) was used to analyze survey data (AMOS 7.0). To assure the quality of research, reliability and validity are often considered as indicators of how good a piece of research is. While reliability is concerned with the accuracy of the actual measuring instrument or procedure, validity is concerned with the study's success at measuring what the researchers set out to measure. Cronbach's $\alpha$ was used for the reliability test, which is a measure of the squared correlation between observed and true scores. If $\alpha$ is greater than 0.7 , it means that it has high reliability and if $\alpha$ is smaller than 0.3 , then it implies that there is low reliability. All Cronbach's $\alpha$ values are displayed in Table 1 . All values in the table are above 0.7 , which means a good level of reliability. This study then performed a confirmatory factor analysis (CFA) to evaluate the convergent validity of the constructs. The results as well as the recommended values for the measures are also shown in Table 1.

Additionally, discriminant validity is shown to be good when the square root of each construct's average variance extracted (AVE) is larger than its correlations with other constructs. As shown in Table 2, the square root of the AVE (written in bold) is much larger than its correlations with other constructs. 
Table 1. Reliability and convergent validity

\begin{tabular}{|c|c|c|c|}
\hline Construct & Factor loadings & Cronbach's $\alpha(>0.7)$ & AVE \\
\hline \multicolumn{4}{|l|}{ PWSQ } \\
\hline PWSQ1 & 0.917 & \multirow{4}{*}{0.860} & \multirow{4}{*}{0.881} \\
\hline PWSQ2 & 0.943 & & \\
\hline PWSQ3 & 1.0 & & \\
\hline PWSQ4 & 0.723 & & \\
\hline \multicolumn{4}{|l|}{ PU } \\
\hline PU3 & 0.708 & \multirow[t]{2}{*}{0.785} & \multirow[t]{2}{*}{0.660} \\
\hline PU4 & 1.0 & & \\
\hline \multicolumn{4}{|l|}{ SAT } \\
\hline SAT1 & 1.0 & \multirow{3}{*}{0.800} & \multirow{3}{*}{0.847} \\
\hline SAT3 & 0.788 & & \\
\hline SAT4 & 0.925 & & \\
\hline \multicolumn{4}{|l|}{ TPR } \\
\hline TPR1 & 0.909 & \multirow[t]{2}{*}{0.753} & \multirow[t]{2}{*}{0.595} \\
\hline TPR2 & 1.0 & & \\
\hline \multicolumn{4}{|l|}{ TRU } \\
\hline TRU1 & 1.0 & \multirow{3}{*}{0.813} & \multirow{3}{*}{0.839} \\
\hline TRU2 & 0.913 & & \\
\hline TRU3 & 0.760 & & \\
\hline \multicolumn{4}{|l|}{ PI } \\
\hline $\mathrm{PI} 2$ & 0.791 & 0.824 & 0.582 \\
\hline PI3 & 1.0 & & \\
\hline
\end{tabular}

Table 2. Inter-construct correlations and discriminant validity

\begin{tabular}{lllllll}
\hline & PWSQ & PU & SAT & TPR & TRU & PI \\
\hline PWSQ & $\mathbf{0 . 9 3 9}$ & & & & & \\
PU & 0.366 & $\mathbf{0 . 8 1 2}$ & & & & \\
SAT & 0.329 & 0.578 & $\mathbf{0 . 9 2 0}$ & & & \\
TPR & 0.281 & 0.338 & 0.386 & $\mathbf{0 . 7 7 2}$ & & \\
TRU & 0.303 & 0.262 & 0.369 & 0.383 & $\mathbf{0 . 9 1 6}$ & \\
PI & 0.415 & 0.465 & 0.633 & 0.380 & 0.409 & $\mathbf{0 . 7 6 3}$ \\
\hline
\end{tabular}

\subsection{Path Analysis and Hypothesis Testing}

The model fit the observed data well. Several model fit indexes conformed to the recommended values. NFI was marginally acceptable at 0.890 and other fit indexes were within acceptable thresholds: GFI=0.912, AGFI=0.873, CFI=0.973, $\mathrm{RMR}=0.048$, and RMSEA=0.044. Fig. 1 shows the standardized path coefficients.

All paths were significant except the path between perceived website quality and satisfaction $(\gamma=0.672, \mathrm{t}=0.786)$, and the path between perceived usefulness and purchase intention $(\gamma=0.160, \mathrm{t}=1.005)$, rejecting $\mathrm{H} 2$ and $\mathrm{H} 8$. The rejection of $\mathrm{H} 2$ is different from the findings of Bai et al. [11]. Perceived website quality has an indirect effect on consumer satisfaction through perceived usefulness. The rejection of $\mathrm{H} 8$ does not meet our initial expectations. Many other studies have shown that perceived 


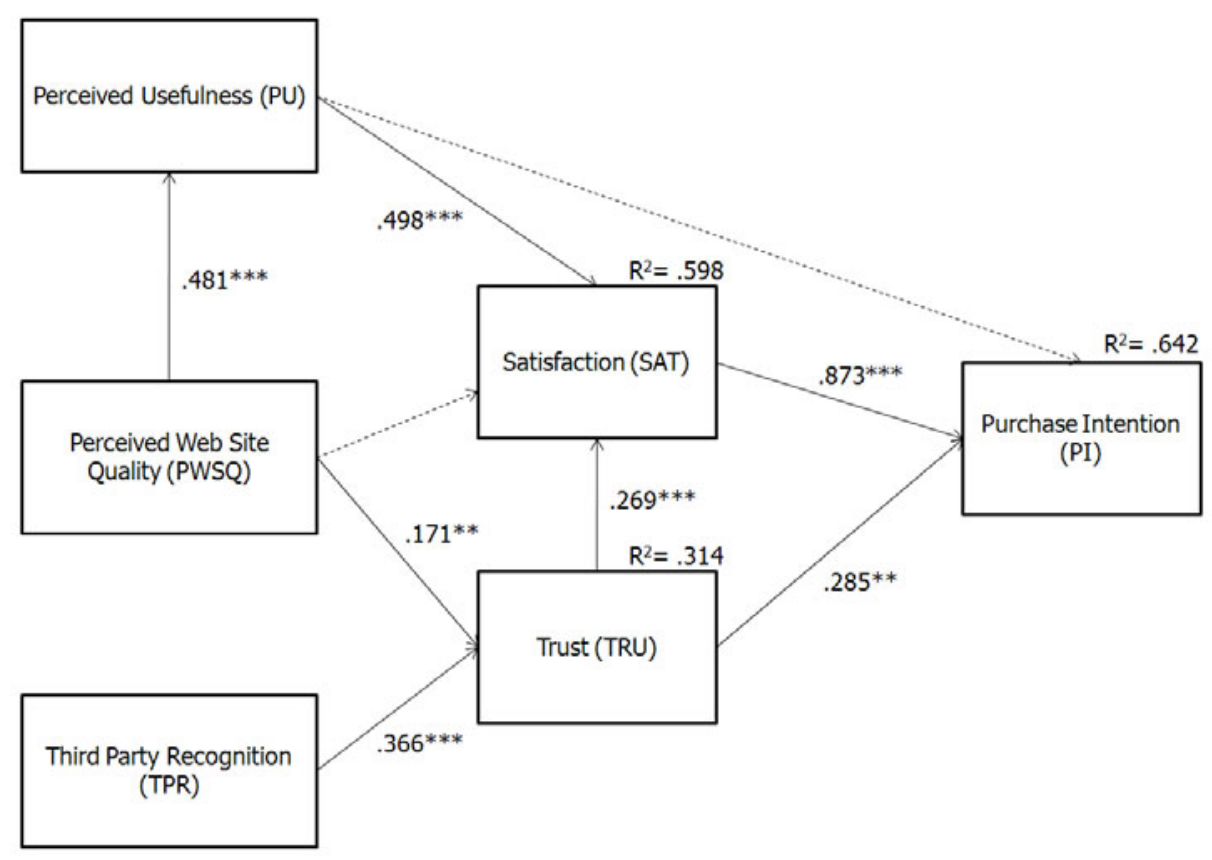

Fig. 1. Results of testing hypotheses $(*: \mathrm{p}<0.1, * *: \mathrm{p}<0.05, * * *: \mathrm{p}<0.01)$

usefulness has a significant and direct impact on purchase intention [1]. In this study perceived usefulness can be found to have an indirect effect on purchase intention only through satisfaction.

The effect of perceived website quality on perceived usefulness ( $\beta=0.481$, $\mathrm{p}<0.01)$ and trust $(\beta=0.171, \mathrm{p}<0.05)$ were significant, validating $\mathrm{H} 1$ and $\mathrm{H} 3$. The adoption of $\mathrm{H} 1$ is consistent with the findings of Liao et al. [10] who verified the significant relationship between perceived website quality and perceived usefulness from the perspective of consumers. The website quality (including color, language, goods information, and transaction system quality) can affect consumers' perceived usefulness. The better quality can make consumers feel that the website is useful to their shopping activity. There are several studies showing that perceived website quality has an effect on trust [3][10]. Website quality can enhance the confidence of buyers toward the vendor. When websites are easy to use and they are filled with quality, buyers would like to depend on the vendor to trust them.

Perceived usefulness was found to influence satisfaction $(\beta=0.498, \mathrm{p}<0.01)$, supporting H4. Previous studies indicated that perceived usefulness significantly influenced consumer satisfaction in online shopping [15]. When consumers feel using open markets can save their time and money, they certainly will be satisfied with $\mathrm{C} 2 \mathrm{C}$ shopping. The effect of third party recognition on trust $(\beta=0.366, \mathrm{p}<0.01)$ was shown to be significant, validating H5. This is consistent with the findings of Jones and Leonard [3]. In open markets, third parties play an important role in dealing, so the third party's reputation seems to reduce uncertainty between buyers and vendors. 
The effect of trust on satisfaction was also significant $(\beta=0.269, \mathrm{p}<0.01)$, validating H6. This result is consistent with the findings of Kim et al. [34], who presented trust had a significant and positive impact on consumer satisfaction. If consumers think a vendor is trustworthy and the information provided by the vendor is reliable, they will feel more satisfied with the open market. Satisfaction $(\beta=0.873, \mathrm{p}<0.01)$ was the strongest predictor of purchase intention, followed by trust $(\beta=0.285$, $\mathrm{p}<0.05$ ), supporting H7, H9. The adoption of $\mathrm{H} 7$ confirms the findings of Bai et al. [11]. When consumers are satisfied with the open market and feel it is a good place to trade, they will be willing to participate in $\mathrm{C} 2 \mathrm{C}$ transactions. The acceptance of H9 meets the findings of Gefen and Straub [35], which were based on the B2C environment.

\section{Conclusions}

This study has developed and empirically tested a theoretical model of $\mathrm{C} 2 \mathrm{C}$ online shopping adoption in the open market. The results validated that $\mathrm{C} 2 \mathrm{C}$ purchase intention was determined by perceived website quality, perceived usefulness, third party recognition, satisfaction, and trust. The results supported seven hypotheses.

The hypothesis-testing results showed perceived website quality significantly affected user perception of usefulness and trust. Therefore, online businesses that run open markets on the Internet should develop several capabilities including convenient transaction information search, easy transaction methods, and fast system access, to improve the perception of usefulness and trust. However, the results showed that perceived website quality did not significantly contribute to consumer satisfaction. A possible explanation is that satisfaction in the open market depends on transaction experiences, which are the most noticeable uncertainty related to trust, because users may overlook website quality.

The results also showed that perceived usefulness did not affect purchase intention. A possible explanation is that the responders in this study were consumers who have had several purchase experiences in open markets. Since they know that there are risks involved in $\mathrm{C} 2 \mathrm{C}$ e-commerce, low price may be the only factor to influence new users' purchase intention. However, perceived usefulness was still an important issue related to purchase intention and the findings showed perceived usefulness influenced purchase intention indirectly through satisfaction. Third party recognition seems to have a significant effect on trust. This means that consumers in this study did care about third parties, their reputation, vendor evaluation system, and the number of successful transactions.

\section{References}

1. He, D.H., Lu, Y.B., Zhou, D.Y.: Empirical study of consumers' purchase intentions in C2C electronic commerce. Tsinghua Science and Technology 13, 287-292 (2008)

2. Vijayasarathy, L.R.: Predicting consumer intentions to use on-line shopping: the case for an augmented technology acceptance model. Information and Management 41, 747-762 (2004) 
3. Jones, K., Leonard, L.N.K.: Trust in consumer-to-consumer electronic commerce. Information and Management 45, 88-95 (2008)

4. Davis, F.D.: Perceived usefulness, perceived ease of use, and user acceptance of information technology. MIS Quarterly 13, 319-340 (1989)

5. Poddar, A., Donthu, N., Wei, Y.J.: Web site customer orientations, Web site quality, and purchase intentions: the role of web site personality. Journal of Business Research 62, 441-450 (2009)

6. Szymanski, D.M., Hise, R.T.: e-Satisfaction: an initial examination. Journal of Retailing 76, 309-322 (2000)

7. Jeong, M., Lambert, C.: Adaptation of an information quality framework to measure customers' behavioral intentions to use lodging Web sites. International Journal of Hospitality Management 20, 129-146 (2001)

8. McKnight, D.H., Chervany, N.L.: What trust means in e-commerce customer relationships: an interdisciplinary conceptual typology. International Journal of Electronic Commerce 6, 35-59 (2002)

9. Schlosser, A.E., White, T.B., Lloyd, S.M.: Converting web site visitors into buyers: how web site investment increases consumer trusting beliefs and online purchase intentions. Journal of Marketing 70, 133-148 (2006)

10. Liao, C.C., Palvia, P., Lin, H.N.: The roles of habit and web site quality in e-commerce. International Journal of Information Management 26, 469-483 (2006)

11. Bai, B., Law, R., Wen, I.: The impact of website quality on customer satisfaction and purchase intentions: evidence from Chinese online visitors. International Journal of Hospitality Management 27, 391-402 (2008)

12. Everard, A., Galletta, D.F.: How presentation flaws affect perceived site quality, trust, and intention to purchase from an online store. Journal of Management Information Systems 22, 55-95 (2006)

13. Fishbein, M., Ajzen, I.: Belief, attitude, intention and behavior: an introduction to theory and research, Reading, MA (1975)

14. Adamson, I., Shine, J.: Extending the new technology acceptance model to measure the end user information systems satisfaction in a mandatory environment: a bank's treasury. Technology Analysis and Strategic Management 15, 441-455 (2003)

15. Lee, H.S., Choi, S.Y., Kang, Y.S.: Formation of e-satisfaction and repurchase intention: Moderating roles of computer self-efficacy and computer anxiety. Expert Systems with Application 36, 7848-7859 (2009)

16. Lee, M.K.O., Turban, E.: A trust model for consumer Internet shopping. International Journal of Electronic Commerce 6, 75-91 (2001)

17. Sultan, F., Venkatesh, S., Urban, G.L.: Online trust: A stakeholder perspective, concepts, implications and future directions. Journal of Strategic Information System 11, 325-344 (2002)

18. Gefen, D., Harris, L., Goode, M.: The four levels of loyalty and the pivotal role of trust: a study of online service dynamics. Journal of Retailing 80, 139-158 (2004)

19. McKnight, D.H., Choudhury, V., Kacmar, C.: Developing and validating trust measures for e-commerce: an integrative typology. Information Systems Research 13, 334-359 (2002)

20. Wakefield, R., Whitten, D.: Examining user perceptions of third-party organization credibility and trust in an e-retailer. Journal of Organizational and End User Computing 18, 1-19 (2006)

21. Ajzen, I., Fishbein, M.: Understanding attitudes and predicting social behavior. PrenticeHall, Englewood Cliffs (1980) 
22. Chow, S., Holden, R.: Toward an understanding of loyalty: the moderating role of trust. Journal of Managerial Issues 9, 275-299 (1997)

23. Singh, J., Sirdeshmukh, D.: Agency and trust mechanisms in consumer satisfaction and loyalty judgments. Journal of the Academy of Marketing Science 28, 150-167 (2000)

24. Jin, B., Park, J.Y.: The moderating effect of online purchase experience on the evaluation of online store attributes and the subsequent impact on market response outcomes. Advances in Consumer Research 33, 203-211 (2006)

25. Zeithaml, L.B., Parasuraman, A.: The behavioral consequences of service quality. Journal of Marketing 60, 31-46 (1996)

26. Ajzen, I., Driver, B.E.: Application of the theory of planned behavior to leisure choice. Journal of Leisure Research 24, 207-224 (1992)

27. Fournier, S., Mick, D.G.: Rediscovering satisfaction. Journal of Marketing 63, 5-23 (1999)

28. Thong, J.Y.L., Hong, S.J., Tam, K.Y.: The effects of post-adoption beliefs on the expectation-confirmation model for information technology continuance. International Journal of Human-Computer Studies 64, 799-810 (2006)

29. Yang, Z., Peterson, R.T.: Customer perceived value, satisfaction, and loyalty: the role of switching costs. Psychology and Marketing 21, 799-822 (2004)

30. Qiu, L.Y., Li, D.: Applying TAM in B2C e-commerce research: an extended model. Tsinghua Science and Technology 13, 265-272 (2008)

31. Williamson, O.E.: Markets and Hierarchies. Free Press, New York (1975)

32. Sirdeshmukh, D., Singh, J., Sabol, B.: Consumer trust, value, and loyalty in relational exchanges. Journal of Marketing 66, 15-37 (2002)

33. Gefen, D., Heart, T.: On the need to include national culture as a central issue in Ecommerce trust beliefs. Journal of Global Information Management 14, 1-30 (2006)

34. Kim, J.Y., Jin, Y.H., Swinney, J.L.: The role of etail quality, e-satisfaction and e-trust in online loyalty development process. Journal of Retailing and Consumer Services 16, 239 247 (2009)

35. Gefen, D., Straub, D.W.: Consumer trust in B2C e-commerce and the importance of social presence: experiments in e-Products and e-Services. Omega 32, 407-424 (2004) 